\title{
ADMINISTRAÇÃO DE VACINAS
}

Mirian Martho de Moura'

ORCID: 0000-0002-6995-7703

Evelin Placido dos Santos'

ORCID: 0000-0002-6152-0072

Mayra Martho Moura de Oliveira' ORCID: 0000-0002-6965-9204

Marcela Aparecida Basílio'

ORCID: 0000-0003-0638-2989

'Sociedade Brasileira de Imunizações - SBIm. São Paulo, SP.

Como citar:

Moura MM, Santos EP, Oliveira MMM, et al. Administração de vacinas. In: Silva TMR, Lima MG, (Org.). Estratégias de vacinação contra a COVID-19 no Brasil: capacitação de profissionais e discentes de enfermagem. Brasília, DF: Editora ABen; 2021. P 52-64. (Série enfermagem e pandemias, 6). https://doi.org/10.51234/aben.21.e08.c06

Revisor: Clebson Verissimo da Costa Pereira. Enfermeiro. Especialista em Infectologia.

\section{INTRODUÇÃO}

Um dos objetivos da vacinação é assegurar que as vacinas alcancem o máximo de imunidade com o mínimo de dano possível para os indivíduos que as recebem. Para isso é necessário o conhecimento técnico e científico dos profissionais de enfermagem que atuam nas ações de imunização. O sucesso na efetividade das vacinas depende de diversos fatores, dentre eles: o sistema imunológico da pessoa vacinada, características do próprio imunobiológico, o correto armazenamento e conservação em todas as instâncias da cadeia de frio, o momento oportuno para o recebimento da vacina e a via de administração recomendada pelo fabricante do produto.

\section{ASPECTOS GERAIS}

A técnica de aplicação de uma vacina, sem dúvida, merece atenção especial, porém outros aspectos são importantes e devem ser observados durante o processo de vacinação:(1-3)

- O atendimento e atenção ao indivíduo fazem diferença, sempre lembrar que diferentes pessoas têm diferentes necessidades.

- A orientação, deve ser sempre objetiva, concisa e desprovida de informações supérfluas. As dúvidas, explícitas ou implícitas, devem ser dissipadas, considerando que ansiedade e o medo de injeção são comuns em qualquer idade.

- O ambiente deve ser acolhedor e inspirar confiança. As áreas de conservação e aplicação devem transmitir a imagem de qualidade em todos os momentos.

É importante lembrar que a vacinação não se limita apenas ao ato de aplicar a vacina, pois consiste em rotinas antes, durante e após a administração do imunobiológico. 
Essas ações repetitivas, bem conhecidas e, na maioria das vezes, sem intercorrências, podem levar à desconsideração do seu potencial para problemas; portanto, é fundamental estabelecer uma série de procedimentos num serviço de imunização, para que possa diminuir erros de imunização.

Antes da vacinação o profissional de enfermagem deve:

- Orientar sobre os possíveis eventos adversos;

- Responder a todos os questionamentos do paciente;

- Consultar os registros (carteira de vacinação) do paciente, quando disponíveis;

- Preencher todos os documentos referentes a administração da vacina.

\section{APRESENTAÇÃO DAS VACINAS}

As vacinas são usualmente apresentadas em seringas ou em frascos já preenchidos com uma única dose ou em frascos que contêm múltiplas doses. Em relação as vacinas contra COVID-19, elas podem apresentar-se nas formas líquidas, congeladas ou liofilizadas. Essas duas últimas necessitam de diluição ou reconstituição com diluente específico de acordo com recomendações do laboratório produtor ${ }^{(1-3)}$.

A homogeneização deve ser feita antes de aspirar a vacina para ser aplicada, mesmo aquelas já na forma líquida e em seringas preenchidas ${ }^{(1-3)}$.

As vacinas com sais de alumínio em sua composição, em particular, devem ser agitadas suavemente para que ocorra homogeneização da solução, que tende a apresentar depósito, se evitam assim reações locais como dor e formação de nódulo ou mesmo abscesso frio ${ }^{(1-3)}$.

O manuseio dos frascos multidoses necessitam ter cuidados redobrados, pois a manipulação e preparo inadequados podem determinar a contaminação, uma vez que, após a primeira manipulação, apresentam soluções de continuidade com o meio exterior, portanto nunca poderão permanecer imersos em água, devendo estar sempre limpos e $\operatorname{secos}^{(1-3)}$.

- Quando transportados, tomar cuidado para que não ocorra contato direto com a bobina de gelo;

- Antes da aspiração de cada dose, submeta o frasco a movimentos de rotação, para homogeneização. A cada aspiração, deve-se perfurar a tampa de borracha em pontos diferentes, evitando a parte central;

- Não aspirar frascos diferentes na mesma seringa para completar doses;

- As vacinas devem ser reconstituídas e aspiradas, imediatamente, antes da administração. Múltiplas doses de vacinas não podem ser aspiradas previamente e armazenadas, para que não haja riscos de contaminação.

\section{REDUZINDOA DOR E A ANSIEDADE}

Questões de segurança e a necessidade de múltiplas injeções aumentam as preocupações e a ansiedade, associadas com a imunização. Os profissionais precisam demonstrar autoconfiança e estabelecer uma relação que promova segurança tanto da pessoa a ser vacinada quanto para seus familiares ${ }^{(4-6)}$.

Embora a dor da aplicação das vacinas seja, até certo ponto, inevitável, há algumas estratégias que os pais e os profissionais podem utilizar para minimizar essa situação, trabalhando para oferecer uma vacinação segura e o menos estressante possível. Os pais, ou responsáveis, devem ser instruídos sobre como auxiliar. O apoio do vacinador, nesse momento, é fundamental para assegurar a compreensão, para que a vacina seja administrada com segurança. Isso é, particularmente, relevante na vacinação de crianças ${ }^{(4-6)}$.

Alguns trabalhos demonstraram que a amamentação é um potente analgésico para lactentes, durante a coleta de sangue, e que pode ajudar, também, a diminuir a dor durante a vacinação ${ }^{(4-6)}$.

O uso de solução de glicose ou sacarose, $12 \%$ a $50 \%$, mostrou ser eficaz para diminuir a dor nos procedimentos em neonatos e bebês até 6 meses. Devendo ser administrado logo antes do procedimento, através 
da instilação com uma seringa diretamente à boca ${ }^{(4,6)}$. Essa recomendação já consta de alguns manuais de vacinação ${ }^{(1-3)}$.

A vacinação com a criança no colo dos pais e os adolescentes e adultos sentados, também pode ajudar na redução da dor ${ }^{(6)}$.

Outro aspecto, é a ordem de aplicação: quando mais de uma vacina for aplicada no mesmo dia, vacinas mais dolorosas devem ser administradas por último ${ }^{(5-6)}$.

O uso de pressão manual no local da injeção, durante 10 segundos, antes da inserção da agulha, também está relacionado com a redução da dor. Uma outra atitude que pode contribuir, é a fricção ou estimulação tátil, próximo ao local da injeção, no momento da administração da vacina, podendo ser realizada pela mãe ou acompanhante do vacinado ${ }^{(6)}$.

\section{CUIDADOS GERAIS}

Quando falamos de cuidados gerais em vacinação, pensamos primeiramente a cerca da segurança do paciente. Esse conjunto de medidas visa prevenir e reduzir a incidência de agravos e eventos adversos resultantes do processo de vacinação.

\section{Higiene das mãos}

A higiene das mãos é um procedimento de fundamental importância que necessita ser realizado antes de cada administração e deve ser repetido ao final de toda a aplicação. As mãos devem ser lavadas sempre com o sabão e água corrente, quando as mãos estiverem visivelmente sujas. Quando as mãos não apresentarem sujidade visível, a higiene pode ser feita com uma solução antisséptica sem água e a base de álcool glicerinado a $70 \%$ quando da administração de cada vacina ${ }^{(3-7)}$.

Certifique-se de que as mãos estejam secas antes de iniciar qualquer atividade.

Para uma correta higiene das mãos, é necessário que:

- Antes de iniciar a higiene das mãos retirar joias, como anéis e pulseiras, pois sob tais objetos podem se acumular micro-organismos.

- Importante, também, manter as unhas curtas para evitar acidentes e acumulo de sujidades.

\section{Uso de luvas}

De acordo com as normas e recomendações nacionais e internacionais atuais, o uso de luvas não é necessário, a não ser que o profissional de saúde tenha lesões abertas nas mãos, o que fará com que entre em contato com líquidos, potencialmente, infecciosos. Cabe enfatizar que, o uso de luvas, quando indicado, não substitui a higiene das mãos. Se as luvas forem utilizadas, deverão ser trocadas a cada paciente. Uso de luvas não protege contra a picada da agulha ou outras lesões derivadas da perfuração, por material perfurocortante ${ }^{(1-7-8)}$.

\section{Uso de antisséptico}

A necessidade, ou não, da antissepsia da pele, na administração de injeções, tem sido objeto de estudos há muito tempo, principalmente em relação ao preparo da pele, antes da aplicação de insulina. As recomendações atuais do Manual de Procedimentos para Vacinação, do Ministério da Saúde, da Organização Mundial da Saúde e de alguns países, tais como, Reino Unido, Austrália e Nova Zelândia, são que a antissepsia da pele, antes da administração de vacinas, não é necessária ${ }^{(2-3,7)}$. 
O preparo do local de aplicação pode ser feito pela limpeza com água e sabão, se houver sujeira perceptível(2-3-7)

Quando da utilização de antissépticos, devemos utilizá-los da maneira correta, de acordo com as recomendações do fabricante. Entre os antissépticos disponíveis para a antissepsia da pele, o álcool etílico a 70\% é o que apresenta maior segurança e eficácia, com melhor custo-benefício, baixa toxicidade, facilidade de aquisição, aplicação e evapora rapidamente, sendo uma vantagem, pois o antisséptico deverá secar antes da aplicação das vacinas. O contato do álcool a $70 \%$ com a pele deve ser de 30 segundos, para melhor eficácia (7).

\section{Descarte de resíduos}

O material utilizado na sala de vacinas, deve ser acondicionado e descartado conforme as definições estabelecidas na RDC Anvisa n²22, de 18 de março de 2018, que Regulamenta Boas Práticas de Gerenciamento de Resíduos de serviços de saúde (RSS), e dá outras providencias. No Art. 47 cita que "Os RSS resultantes de atividades de vacinação com microrganismos vivos, atenuados ou inativados incluindo frascos de vacinas com expiração do prazo de validade, com conteúdo inutilizado ou com restos de produto e seringas, quando desconectadas, devem ser tratados antes da disposição final"(9).

É responsabilidade do trabalhador da sala de vacinação realizar a segregação, o acondicionamento e a identificação de tais resíduos ${ }^{(9)}$.

Todo serviço gerador de resíduo de saúde deve dispor de um Plano de Gerenciamento de RSS (PGRSS), observando as regulamentações federais, estaduais, municipais ou do Distrito Federal. O PGRSS deve ser monitorado e mantido atualizado, conforme periodicidade definida pelo responsável por sua elaboração e implantação(9).

\section{Resíduos resultantes da atividade de vacinação}

- Resíduos infectantes, classificados como resíduos do Grupo A1, que contêm na sua formulação microrganismos vivos ou atenuados, incluindo frascos de vacinas com prazo de validade expirado, vazios ou com sobras de vacinas e, ainda agulhas e seringas utilizadas ${ }^{(9)}$.

- Resíduos comuns, também classificados como resíduos do Grupo D, que são caracterizados por não apresentarem risco biológico, químico ou radiológico à saúde ou ao meio ambiente, podendo ser equiparados aos resíduos domiciliares (papel, embalagens de seringas e agulhas ${ }^{(9)}$.

\section{Etapas do Manejo}

Segregação, Acondicionamento, Identificação; Coleta e transporte interno; Armazenamento interno, temporário e externo; Coleta e transporte externos, Destinação ${ }^{(9)}$.

Os sacos e recipientes para acondicionamento de RSS devem ser substituídos ao atingirem o limite de sua capacidade de acordo com a orientação do seu fabricante. Destacamos alguns aspectos fundamentais, tais como:

- Acondicionar na caixa para descarte de materiais perfurocortantes, os resíduos especiais, como seringas e agulhas descartáveis usadas.

- Utilizar a caixa de material perfurocortante até completar 2/3 (dois terços) de sua capacidade, independentemente do número de dias de trabalho.

- Colocar os recipientes coletores para o descarte de material perfurocortante próximo ao local onde é realizado o procedimento.

- Nunca reencapar, entortar, quebrar ou retirar manualmente as agulhas das seringas.

- Seringas e agulhas com dispositivo de segurança também devem ser descartadas na caixa coletora de material perfurocortante. 


\section{VIAS E LOCAIS DE APLICAÇÃO}

Vacinas e outros imunobiológicos são geralmente aplicados por via parenteral, sendo as vias intramuscular e subcutânea as mais frequentemente utilizadas. Todas as vacinas contra COVID-19, até o momento, estão licenciadas pelos órgãos regulatórios, para uso exclusivo da via intramuscular ${ }^{(1-3)}$.

\section{Via Intramuscular (IM)}

A via intramuscular (IM) é, sem dúvida, aquela que suscita maiores dúvidas e levanta maiores polêmicas e também a via mais utilizada em vacinas. A região glútea é contraindicada, e a origem desta orientação se baseia em estudos anatômicos que mostram o risco de lesão do nervo ciático e no fato de que, em crianças que ainda não andam, a musculatura glútea não é desenvolvida, sendo essa região constituída essencialmente de tecido adiposo, o que levaria a uma absorção inadequada como com a vacina hepatite B (recombinante) e vacina raiva (inativada), portanto essas vacinas têm contraindicação formal para administração no glúteo ${ }^{(2-3,11)}$.

Os locais selecionados devem estar distantes dos grandes nervos e vasos sanguíneos, sendo os mais utilizados o músculo vasto lateral da coxa e o músculo deltoide. A região do ventroglúteo é um local alternativo para a vacinação intramuscular de crianças, adolescentes e adultos. Os vacinadores que escolherem este local devem estar familiarizados com a delimitação. A reatogenicidade e a imunogenicidade, das vacinas dadas neste local, são comparáveis às das vacinas administradas na região vasto lateral da coxa ${ }^{(2-3,11)}$.

\section{TÉCNICA DE APLICAÇÃO IM}

Independentemente da localização, a frequência de reações colaterais e de eventos adversos depende da técnica de aplicação, do preparo adequado da vacina a ser aplicada e da escolha adequada da agulha. Quanto à técnica de aplicação, o emprego da técnica em $Z$ e o adequado posicionamento do indivíduo e o relaxamento do músculo escolhido são fundamentais. ${ }^{(2-3,11)}$

\section{Escolha da agulha para aplicação intramuscular}

A agulha deve ser escolhida tendo em vista a espessura da camada subcutânea e a distância entre a pele e as estruturas ósseas subjacentes. O ângulo de aplicação deve ser adequado ao tamanho da agulha. A cada aplicação deve ser feita uma avaliação individual para definir qual o tamanho da agulha ideal. As vacinas devem atingir o tecido desejado para fornecer uma resposta imunológica ideal e reduzir a probabilidade de reações no local da injeção. Um suprimento de agulhas deve estar disponível em vários comprimentos apropriados para a população de pacientes a serem vacinados. De modo geral, as agulhas para administração intramuscular variam de 20 × 5,5 dec/mm, 25 × 6,0 dec/mm; 25 x 7,0 dec/mm; 25 x 8,0 dec/mm e 30 x $7,0 \mathrm{dec} / \mathrm{mm}^{(10-11)}$.

\section{Técnica em Z}

Consiste em realizar uma tração aplicada à pele e aos tecidos subcutâneos antes da inserção da agulha e depois liberá-la após a retirada da agulha. Dessa forma a rota da injeção superficial ao músculo fica deslocada da rota dentro do músculo, selando a medicação no mesmo não havendo, portanto, retorno do líquido para o subcutâneo, diminuindo a dor e a incidência de lesões. Outra técnica aceitável para pacientes com musculatura pouco desenvolvida assim como, geriátricos, debilitados e pediátricos é pinçar o tecido do local da administração com o dedo indicador e o polegar, mantendo a região firme e aplicar a vacina ${ }^{(11)}$. 


\section{Posicionamento do cliente para o relaxamento do músculo}

O posicionamento do músculo de modo que relaxe mostrou ser capaz de diminuir a dor e o desconforto da injeção ${ }^{(11)}$.

\section{Vasto lateral da coxa}

- Dobrar o joelho levemente, para promover o relaxamento do músculo alvo, quando deitado;

- Colocar os lactentes e crianças no colo de um dos pais ou responsável, com a perna apoiada no colo, pois assim relaxam melhor;

\section{Deltoide}

- Evitar roupas apertadas acima do local da aplicação, deixando o membro exposto;

- Rebaixar o ombro e realizar flexão do braço para poder relaxá-lo;

- Sentar as crianças mais velhas no colo dos pais, abraçando-os peito com peito. Os pais devem segurar o antebraço, ficando assim relaxado, mais confortável e seguro.

\section{Administração intramuscular}

- Realizar a higiene das mãos ${ }^{(2-3,11)}$

- Escolher a agulha de acordo com a idade do paciente e espessura do subcutâneo e região muscular;

- Escolher a região muscular de acordo com a idade do paciente e conforme a indicação do fabricante;

- Realizar a técnica em Z, fazer a tração da pele e ao tecido subcutâneo antes da aplicação e liberar após a administração da vacina. Em idosos e subnutridos, muitas vezes não possuem tecido muscular suficiente para o uso da Técnica em $Z$ e nesses casos necessita agrupar o músculo.

- Introduzir preferencialmente a agulha em ângulo de $90^{\circ}$, podendo variar de acordo com o tamanho da agulha e tamanho do subcutâneo. A agulha deve ser introduzida de modo suave e seguro através da pele e do tecido subcutâneo em direção ao músculo;

- Retirar a agulha com um movimento suave e firme, aplicando uma leve pressão com algodão seco;

- Observar o vacinado;

- Descartar os materiais adequadamente;

- Realizar a higiene das mãos.

\section{CUIDADOS APÓS ADMINISTRAÇÃO DE VACINAS}

Os profissionais de saúde devem estar bem informados sobre as políticas e procedimentos para identificar e relatar eventos adversos após a vacinação. Um evento adverso da vacina refere-se a qualquer evento que possa ocorrer após a vacinação, que pode ou não estar relacionado à vacinação. Serão necessárias avaliações adicionais para determinar se um evento adverso é causado por uma vacina ${ }^{(1-3)}$.

Todas as vacinas utilizadas nos programas nacionais de imunização, em princípio, são seguras e eficazes. Concretamente, no entanto, nenhuma vacina é completamente livre de riscos e eventos adversos. Por esse motivo, é de fundamental importância a vigilância aos eventos adversos pós-vacinação.

As reações adversas potencialmente fatais que podem ocorrer imediatamente após a vacinação são reações alérgicas graves (anafilaxia) e síncope (desmaios). 


\section{Gerenciando reações agudas após vacinação}

Uma reação aguda na sala de vacinação pode ser reconhecida também como uma emergência, dependendo do grau de comprometimento da sua saúde ou risco de vida do paciente. É imprescindível que a equipe que atua em sala de vacina conheça e se antecipe aos sinais enviados pelo paciente e a investigação realizada na triagem.

\section{Anafilaxia}

Reações anafiláticas graves com risco de vida após a vacinação são raras. A triagem minuciosa para contraindicações e precauções antes da vacinação pode frequentemente prevenir essas reações. Os profissionais de saúde devem estar familiarizados com a identificação de reações alérgicas de tipo imediato. Os sintomas dessas reações incluem urticária local ou generalizada (urticária), angioedema, comprometimento respiratório devido a sibilos ou inchaço da garganta, hipotensão e choque ${ }^{(1-2)}$.

Todo serviço de imunização deve ter material de emergência e os profissionais de enfermagem capacitados para o reconhecimento e condutas ao atendimento da reação anafilática e devem ser competentes no tratamento desses eventos no momento da administração da vacina. Os locais que administram vacinas devem ter um plano para entrar em contato com os serviços médicos de emergência imediatamente se houver uma reação anafilática à vacinação, e os membros da equipe devem conhecer suas funções individuais em caso de uma emergência.

Na prática clínica, muitos termos relacionados são utilizados, tais como, reação anafilática, reação anafilactóide e choque anafilático.

Choque anafilático é a manifestação mais grave da anafilaxia. É definido como uma síndrome clínica, caracterizada por hipoperfusão tissular, com sinais e sintomas de insuficiência hemodinâmica.

O aparecimento: a maioria dos casos acontece na primeira hora (de segundos a minutos após a exposição) e uma menor quantidade de casos após 12 horas de exposição. Existem relatos de apresentação bifásica em um prazo de até 72 horas.

\section{Síncope após a vacinação}

A síncope, reação vasovagal, após injeção é uma reação conhecida, sendo mais comum em adultos e adolescentes. Aproximadamente $60 \%$ dessas reações acontecem nos cinco minutos posteriores à vacinação e cerca de $90 \%$ ocorrem em 15 minutos. O profissional de saúde deve estar ciente dos fatores predisponentes (fobia de agulhas e injeções, idade) e manifestações de pré-síncope (ansiedade, sudorese) e estar atento para prevenir quedas ${ }^{(1-12)}$.

Cuidados para evitar e/ou atender a síncope:

- Observar o paciente, principalmente adolescentes e adultos que apresentam sinais predisponentes;

- Vacinar esses pacientes sempre sentados ou até mesmo deitados;

- Observar pelo menos 15 minutos após a vacinação.

Caso a sincope ocorra, o paciente deve ser protegido de quedas e deve ser deitado de costas, com as pernas erguidas, até o desaparecimento dos sintomas.

Os profissionais de saúde são obrigados por lei a relatar eventos adversos à vacinação e são incentivados a relatar outros eventos, após a vacinação para o Sistema de Notificação de Eventos Adversos de Vacinas (EAPV). 


\section{VACINAÇÃO CONTRA COVID-19}

As vacinas de COVID-19 atualmente utilizadas no Brasil são ${ }^{(15)}$ :

- Instituto Butantan (IB): vacina adsorvida COVID-19 (Inativada) Fabricante: Sinovac Life Sciences Co., Ltd. Parceria: Sinovac/Butantan.

- Fundação Oswaldo Cruz - Instituto de Tecnologia em Imunobiológicos - Bio-Manguinhos (Fiocruz/Bio Manguinhos): vacina COVID-19 (recombinante) Fabricante: Serum Institute of Índia Pvt. Ltd. Parceria: AstraZeneca/Fiocruz.

- Fundação Oswaldo Cruz - Instituto de Tecnologia em Imunobiológicos - Bio-Manguinhos (Fiocruz/ Bio-Manguinhos): vacina COVID-19 (recombinante) Fabricante: Fiocruz/Bio-Manguinhos. Parceria: AstraZeneca/Fiocruz.

- AstraZeneca: vacina contra COVID-19 (ChAdOx1-S (recombinante)). Vacina oriunda do consórcio Covax Facility.

- Pfizer/Wyeth: vacina COVID-19 (RNAm) a Comirnaty produzida na Bélgica e a Pfizer-BioNTech produzida nos EUA.

- Janssen produzida nos EUA, vacina COVID-19 (recombinante).

Considera-se esquema completo a aplicação das duas doses (D1+D2) das vacinas, respeitando os intervalos preconizados ${ }^{(13,15)}$.

A vacina Janssen é a única com recomendação para administração, até o momento, de uma única dose.

- Vacina Sinovac/Butantan: intervalo entre as doses, de 02 a 04 semanas.

- Vacina AstraZeneca/Fiocruz: intervalo entre as doses,12 semanas.

- Vacina Comirnaty/Pfizer BioNTech: segundo a bula o intervalo é de 21 dias e conforme orientações do Ministério da Saúde do Brasil, em consonância com os programas do Reino Unido e do Canadá, estabeleceu e recomenda o intervalo de 12 semanas entre a primeira e a segunda dose da vacina.

- Vacina Janssen dose única, até o momento.

\section{Triagem}

Antes da administração conferir possíveis contraindicações e pontos de precauções, como:

\section{Contraindicações}

Contraindicações à administração das vacinas COVID-19(13-15):

- Hipersensibilidade ao princípio ativo ou a qualquer dos excipientes da vacina;

- Para aquelas pessoas que já apresentaram uma reação anafilática confirmada a uma dose anterior de uma vacina COVID-19;

- Para a vacina COVID-19 (recombinante) - AstraZeneca acrescenta-se a seguinte contraindicação: pacientes que sofreram trombose venosa e/ou arterial importante em combinação com trombocitopenia após vacinação com qualquer vacina para a COVID-19

- Para as vacinas COVID-19 recombinantes dos fabricantes AstraZeneca e Janssen acrescenta-se a seguinte contraindicação: pessoas com histórico de síndrome de extravasamento capilar.

- Miocardite e pericardite: Casos muito raros de miocardite e pericardite foram relatados após vacinação com Comirnaty/Pfizer BioNTech. Normalmente, os casos ocorreram com mais frequência em homens mais jovens e após a segunda dose da vacina e em até 14 dias após a vacinação. Geralmente são casos leves e os indivíduos tendem a se recuperar dentro de um curto período de tempo após o tratamento padrão e repouso. Os profissionais de saúde devem estar atentos aos sinais e sintomas de miocardite e pericardite em vacinados. 
- Trombocitopenia e distúrbios da coagulação: Tal como em outras injeções intramusculares, a vacina deve ser administrada com cautela em indivíduos que estejam recebendo tratamento anticoagulante ou que apresentem trombocitopenia ou qualquer distúrbio da coagulação (tal como hemofilia), uma vez que pode ocorrer hemorragia ou hematoma após uma administração intramuscular nestes indivíduos.

\section{Precauções}

Em pessoas com histórico de anafilaxia, ou seja, reação grave a outras vacinas, recomenda-se uma observação atenta durante, pelo menos, 15 minutos após a vacinação. Não se deve administrar uma segunda dose da vacina a indivíduos que apresentaram anafilaxia à primeira dose da vacina ${ }^{(13-15)}$.

Importante verificar qual a vacina administrada na primeira dose, uma vez que as vacinas, até o momento, não são intercambiáveis, ou seja, o esquema deve ser realizado com a mesma vacina nas 2 doses ${ }^{(13-15)}$.

Também é importante verificar se o indivíduo foi vacinado com outras vacinas e em que data foi realizada essas outras vacinações. Isto é importante porque as vacinas utilizadas atualmente não devem ser coadministradas com as demais vacinas do calendário nacional, devendo respeitar o intervalo de 14 dias antes e depois de serem realizadas entre as demais vacinas ${ }^{(13-15)}$.

Considera-se esquema completo a aplicação das duas doses (D1+D2) de todas as vacinas, respeitando os intervalos preconizados ${ }^{(13-15)}$.

As vacinas Coronavac, Covishield (Astra Zenica) e Comirnaty/Pfizer BioNTech são indicadas, no Brasil para pessoas a partir de 18 anos. As vacinas da Pfizer estão registradas no Brasil a partir de 12 anos de idade ${ }^{(13-15)}$.

\section{Conservação e armazenamento}

As vacinas que previnem COVID-19 disponíveis no Brasil possuem algumas diferenças entre si em relação a conservação ${ }^{(13-15)}$.

As vacinas Coronavac e Covishield devem ser mantidas a todo tempo entre as temperaturas de $2^{\circ} \mathrm{Ce} 8^{\circ} \mathrm{C}$. Já a vacina Comirnaty/ Pfizer BioNTech deve ser mantida a $-80^{\circ} \mathrm{C}$ nas centrais de armazenamento, mas na sala de vacinação devem ser mantidas sempre entre $2^{\circ} \mathrm{C}$ e $8^{\circ} \mathrm{C}$ pelo período permitido pelo fabricante. Atualmente esta vacina pode ficar até um mês mantida entre $2^{\circ} \mathrm{C}$ e $8^{\circ} \mathrm{C}$ antes de ser reconstituída ${ }^{(13-15)}$.

Uma informação importante relacionada à conservação da vacina Comirnaty/Pfizer BioNTech é que uma vez descongelada, a vacina não deve ser congelada novamente ${ }^{(13-15)}$.

A vacina COVID-19 (recombinante) da Farmacêutica Janssen, deve ser conservada após a abertura do frasco em temperatura de $2^{\circ} \mathrm{C}$ à $8^{\circ} \mathrm{C}$.

Após a abertura dos frascos, cada vacina tem um período diferente para serem utilizadas, mas este uso só poderá ocorrer se as vacinas continuarem sendo conservadas entre $2^{\circ} \mathrm{C}$ e $8^{\circ}$.

\section{Preparo da vacina}

Após a abertura do frasco multidoses, deve ser realizado o registro da data e hora de abertura no frasco (protegendo a informação do lote e data de validade) ${ }^{(13-15)}$.

\section{Vacina Coronavac COVID-19 (Sinovac/Butantan)}

É uma vacina de vírus inativado, apresentação em frascos-ampola, multidose contendo 10 doses. Esquema vacinal composto por 2 doses de 0,5 ml, intervalo entre as doses de 4 semanas. Deve ser utilizada por até 8 horas após sua abertura em temperatura de $2^{\circ}$ a $8^{\text {o(13-15) }}$. 


\section{Vacina Covishield COVID-19 (AstraZeneca/Fiocruz)}

Vacina de vetor viral recombinante, apresentação frasco ampola multidoses contendo 5 doses. Esquema vacinal composto por 2 doses com intervalo de 12 semanas. Após aberto, o frasco deve ser conservado por 48 horas em temperatura de $2^{\circ}$ a $8^{\circ(13-15)}$.

\section{Vacina AstraZeneca/Fiocruz/Serum Instituto of Índia}

Vacina de vetor viral recombinante, apresentação frasco ampola multidoses contendo 10 doses. Esquema vacinal composto por 2 doses com intervalo de 12 semanas. Após aberto, o frasco deve ser conservado por 6 horas em temperatura de $+2^{\circ} \mathrm{a}+8^{\circ(13-15)}$.

\section{AstraZeneca - COVAX (ChAdOx1-S (recombinante)}

Vacina de vetor viral recombinante, apresentação frasco ampola multidoses contendo 10 doses. Esquema vacinal composto por 2 doses com intervalo de 12 semanas. Após aberto, o frasco deve ser conservado por 6 horas em temperatura de $2^{\circ}$ a $8^{\circ(13-15)}$.

\section{Vacina covid-19 (RNAm) (Comirnaty) - Pfizer/Wyeth}

Vacina COVID-19 (RNA mensageiro) desenvolvida pelo laboratório Pfizer/BioNTech é registrada no Brasil pela farmacêutica Wyeth. Sua apresentação é em frascos multidose, contendo 6 doses em cada frasco, devendo ser diluída em 1,8ml de solução de cloreto de sódio 0,9\% (soro fisiológico), cada dose final será de 0,3mL ${ }^{(13-15)}$.

Atualização de indicação: As alterações de indicação para uso em adolescentes de 12 a 15 anos foram aprovadas pela ANVISA no dia 11 de junho de 2021.

Comirnaty/Pfizer BioNTech deve ser utilizada por até 6 horas após sua abertura desde que conservadas em refrigeração de $+2^{\circ} \mathrm{C} a+8^{\circ} \mathrm{C}$, devendo ser desprezadas se não utilizadas dentro deste período após sua abertura $^{(13-15)}$.

A vacina Comirnaty/Pfizer BioNTech, uma vez descongelada, ou seja, armazenada entre $2^{\circ} \mathrm{C}$ a $8^{\circ} \mathrm{C}$ deve ser diluída com 1,8 $\mathrm{ml}$ de solução de cloreto de sódio $9 \mathrm{mg} / \mathrm{ml}$ (Soro fisiológico 0,9\%).

Vacina COVID-19 (recombinante) - Janssen

A vacina COVID-19 (recombinante) da Farmacêutica Janssen, na composição por dose de 0,5mL. Apresentação Frascos multidose de 5 doses. Esquema vacinal de dose única de 0,5 mL. 6 horas após a abertura do frasco em temperatura de $2^{\circ} \mathrm{C}$ à $8^{\circ} \mathrm{C}$.

\section{Procedimento para a administração das vacinas}

A administração das vacinas será pela via intramuscular (IM), no músculo deltoide, devendo administrar o volume recomendado para cada vacina ${ }^{(13-15)}$ :

- Vacina Sinovac/Butantan: 0,5ml cada dose.

- Vacina Covishield AstraZeneca/Fiocruz, Covishield Sérum Institute e Covishield Astra Zenica (Covax): $0,5 \mathrm{ml}$ cada dose.

- Vacina Comirnaty/Pfizer e BioNTech: 0,3ml cada dose.

- Vacina Janssen: 0,5 ml. 
O local de administração deve ser, preferencialmente, o deltóide, mas o Plano Operacional de Vacinação também coloca como opções o vasto lateral da coxa caso haja algum impedimento ou especificidade e outra área alternativa para a administração é a ventroglútea, devendo ser utilizada por profissionais capacitados ${ }^{(13)}$.

Serão utilizadas para aplicação seringas e agulhas com as seguintes especificações:

- Seringas de plástico descartáveis (de 1,0 ml, 3,0 mL);

- Agulhas descartáveis para uso intramuscular: 25 x 6,0 dec/mm; 25 x 7,0 dec/mm; 25 x 8,0 dec/mm e $30 \times 7,0 \mathrm{dec} / \mathrm{mm}$.

Para aspiração da vacina Comirnaty/Pfizer BioNTech, devem ser preferencialmente utilizadas seringas de $1,0 \mathrm{ml}$ e agulhas de baixo volume morto para extrair 06 (seis) doses de um único frasco ${ }^{(13-14)}$

Se forem utilizadas seringas e agulhas padrão, pode não haver volume suficiente para extrair uma sexta dose de um único frasco. No caso da quantidade de vacina restante no frasco não puder fornecer uma dose completa de 0,3 ml, qualquer volume em excesso deverá ser desprezado ${ }^{(13-14)}$.

O Instituto Butantan também recomenda que seja utilizada seringa de $1 \mathrm{ml}$ de baixo volume morto para facilitar a retirada de 10 doses completas de $0,5 \mathrm{ml}^{(13)}$.

A Vacina Sinovac/Butantan, por se tratar de um produto com adjuvante, (com hidróxido de alumínio), deve ser homogeneizada com movimentos circulares leves. Inspecione o frasco para certificar-se de que o produto esteja realmente diluído ${ }^{(13)}$.

O fabricante da vacina Comirnaty/Pfizer BioNTech, o laboratório Pfizer, recomenda que para esta vacina sejam feitos movimentos de inversão do frasco por 10 vezes, sem agitar o frasco ${ }^{(13-14)}$.

Os frascos das quatro vacinas podem ser manuseados em condições de luz ambiente ${ }^{(13-15)}$.

\section{Cuidados após a administração:}

Comprovante de vacinação: Após a vacinação, todas as pessoas devem receber o comprovante de vacinação, contendo: data (dia, mês e ano), o lote e a unidade de saúde onde a vacina foi administrada, preenchidos a caneta, no espaço reservado do documento de registro individual, além de conter a assinatura e carimbo do vacinador de forma legível ${ }^{(13-15)}$.

No caso de indivíduo com histórico de Síndrome Vasovagal, colocá-lo em observação clínica por pelo menos 15 minutos após a administração da vacina ${ }^{(13-15)}$.

Observar a presença de sangramento ou hematomas após uma administração intramuscular em indivíduos recebendo terapia anticoagulante ou aqueles com trombocitopenia ou qualquer distúrbio de coagulação (como hemofilia). Orienta-se pressionar o algodão no local da aplicação por mais tempo. Caso ocorra sangramento encaminhar para atendimento médico ${ }^{(13-15)}$.

Orientações sobre as possíveis reações pós vacinação: reações comuns: dor no local da injeção, fadiga, mialgia, febre, diarreia, náusea e dor de cabeça ${ }^{(13-15)}$.

\section{CONSIDERAÇÕES FINAIS}

Muito se fala sobre a rapidez no desenvolvimento das vacinas contra COVID-19, porém, as pesquisas prévias para a elaboração de vacinas contra outros coronavírus, o SARS-CoV (2002) e o MERS (2012), e os investimentos realizados por governos dos países desenvolvidos, organizações privadas e multilaterais e empresas farmacêuticas multinacionais contribuíram para acelerar o processo.

Fora de um contexto pandêmico, exige-se que as vacinas tenham eficácia acima de $70 \%$. A Organização Mundial da Saúde (OMS) definiu que uma vacina com proteção acima de $50 \%$ é aceitável, pois esse índice é suficiente para diminuir a circulação do vírus quando altas coberturas vacinais forem alcançadas. 
As fases de desenvolvimento compreendem descoberta pré-clínica, aprovação regulatória, pesquisa clínica (fase I, II e III), aprovação regulatória para registro e acesso. E a farmacovigilância continua após a distribuição da vacina para população.

De nada valem anos e anos de pesquisa e desenvolvimento, a um custo de milhões de dólares, para se obter uma vacina eficaz e segura, se a aplicação é feita de maneira descuidada, levando muitas vezes, não só à redução da eficácia, mas também induzindo eventos adversos perfeitamente evitáveis se a aplicação houvesse sido feita de maneira correta.

O emprego das boas práticas é relevante para minimização de erros e garantia de adequada resposta imune às vacinas para não comprometer o sucesso e credibilidade do Programa Nacional de Imunizações, que tem feito elevado investimento na compra de vacina, logística de distribuição e operacionalização da vacinação no Brasil.

\section{REFERÊNCIAS}

1. Kroger A, Bahta L, Hunter P. General Best Practice Guidelines for Immunization: Best Practices Guidance of the Advisory Committee on Immunization Practices (ACIP) [Internet]. CDC; 2021 [cited 2021 Sep 10]. 193 p. Available from: https://www. cdc.gov/vaccines/hcp/acip-recs/general-recs/downloads/general-recs.pdf

2. Ministry of Health (NZ). Immunisation Handbook [Internet]. Wellington: Ministry of Health; 2020[cited 2021 Sep 10]. Available from: http://www.health.govt.nz/publication/immunisation-handbook-2011

3. Ministério da Saúde (BR). Secretaria de Vigilância em Saúde. Departamento de Vigilância das Doenças Transmissíveis. Manual de Normas e Procedimentos para Vacinação [Internet]. Brasília: Ministério da Saúde; 2014. 176 p. Available from: https://bvsms.saude.gov.br/bvs/publicacoes/manual_procedimentos_vacinacao.pdf

4. Schechter NL, Zempsky WT, Cohen LL, McGrath PJ, McMurtry CM, Bright NS. Pain reduction during pediatric immunizations: evidence-based review and recommendations. Pediatrics. 2007; 119:e1184-98

5. Immunisation Advisory Centre. Mitigating vaccination pain and distress: fact sheet for vaccinators [Internet]. 2016 [cited 2021 Sep 10]. Available from: http://www.immune.org.nz/sites/default/files/AdministrationPainMitigationlmac20160211V01Final.pdf

6. Taddio A, McMurtry CM, Shah V, Riddell RP, Chambers CT, Noel M, et al. Reducing pain during vaccine injections: clinical practice guideline [Internet]. CMAJ. 2015[cited 2021 Sep 10];187(13):975-82. Available from: https://pubmed.ncbi.nlm.nih.gov/26303247/

7. World Health Organization (WHO). Best practices for injections and related procedures toolkit. WHO/EHT/10.02. Geneva: WHO; 2010[cited 2021 Sep 10]. Available from: http://apps.who.int/iris/bitstream/handle/10665/44298/9789241599252_ eng.pdf?sequence $=1$

8. Conselho Regional de Enfermagem de São Paulo (COREN-SP). Parecer Técnico COREN-SP № 01/2021 Ementa: Uso de Equipamento de Proteção Individual (EPI) na sala de vacinação [Internet]. 2021 [cited 2021 Sep 10]. Available from: https:// portal.coren-sp.gov.br/wp-content/uploads/2021/01/PARECER-T\%C3\%89CNICO-N\%C2\%BA-01-2021.pdf

9. Agência de Vigilância Sanitária (Anvisa). Resolução RDC №. 222, de 28 de março de 2018. Regulamenta as Boas Práticas de Gerenciamento dos Resíduos de Serviços de Saúde e dá outras providências [Internet]. 2018[cited 2021 Sep 10]. http://antigo.anvisa.gov.br/documents/33852/271855/RDC+222+de+Mar\%C3\%A7o+de+2018+COMENTADA/ edd85795-17a2-4e1e-99ac-df6bad1e00ce?version=1.0

10. Zuckerman JN. The importance of injecting vaccines into muscle: different patients need different needle sizes. BMJ. 2000;321(7271):1237-8 https://doi.org/10.1136/bmj.321.7271.1237

11. Ballalai I. Manual prático de imunizações. São Paulo: AC. Farmacêutica, 2013.

12. Sutherland A, Izurieta $H$, Ball R, Braun MM, Miller ER, Broder KR, et al. Syncope after vaccination-United States, January 2005-July 2007. MMWR[Internet]. 2008[cited 2021 Sep 10];57:457-460. Available from: https://www.cdc.gov/mmwr/ preview/mmwrhtml/mm5717a2.htm

13. Ministerio da Saude (BR). Secretaria de Vigilancia em Saude. Departamento de Imunizacao e Doencas Transmissiveis. Plano Nacional de Operacionalizacao da Vacinacao contra a Covid-19 [Internet]. Brasilia: Ministerio da Saude; 2021 [cited 2021 Sep 10]. 103 p. Available from: http://bvsms.saude.gov.br/bvs/publicacoes/plano_nacional_operacionalizacao_vacinacao_ covid-19.pdf 
14. Governo do Estado do Ceará. Secretaria de Saúde. Ceará. Nota Técnica. Vacina Covid-19 Pfizer, BioNtec de 01 de maio de 2021 [Internet]. 2021 [cited 2021 Sep 10]. Available from: https://coronavirus.ceara.gov.br/project/ nota-tecnica-vacina-pfizer-biontech/ 